\title{
A PESQUISA NARRATIVA AUTOBIOGRÁFICA DE UMA PROFESSORA DE MATEMÁTICA: APROXIMAÇÕES COM A INSUBORDINAÇÃO CRIATIVA
}

\section{A MATH TEACHER'S AUTOBIOGRAPHICAL NARRATIVE INQUIRY: APPROACHES TO CREATIVE INSUBORDINATION}

\author{
Gabriela Félix Brião \\ Universidade do Estado do Rio de Janeiro / gabriela.felix@gmail.com
}

\section{Resumo:}

Este trabalho é um recorte de minha tese de doutorado. Na pesquisa, busco compreender as minhas práticas docentes, resgatando inúmeros relatos de vida e entrelaçando-os em uma história de vida de uma professora de matemática. Durante a jornada autobiográfica me deparei com auto-insubordinações criativas, contradições vivas e contra-memórias misturados em múltiplos eus-professores que se afirmavam construtivistas. Trago a arquitetura da narrativa, na qual a aprendizagem é seu fio condutor. Esta é uma jornada de empodeiramento e formação que me levou a uma reflexão mais profunda sobre a minha identidade docente. Pesquisas assim contribuem para a ressignificação da docência ao pensar com histórias sobre o tornar-se professor.

Palavras-chave: Pesquisa narrativa autobiográfica. Formação de professores. Educação Matemática. Narrativas de vida de professores.

\begin{abstract}
:
This work is part of my doctoral thesis. In the research, I try to understand my teaching practices, rescuing numerous life stories and interweaving them in a life history of a math teacher. During the autobiographical journey I came across creative self-insubordination, living contradictions and counter-memories mixed in multiple selves' teachers who said constructivists. I bring the architecture of the narrative, in which learning is its thread. This is a journey of empowerment and training that led me to a deeper reflection about my identity. Research in this way contributes to the re-signification of teaching when thinking with stories about becoming a teacher.
\end{abstract}

Keywords: Autobiographical Narrative Inquiry. Teacher Education. Mathematics Education. Narrative History of Teachers. 


\section{O Desafio de Reinventar-se}

Como conta-se uma professora de matemática? Enumerando suas multiplicidades com seus eus-professores (DAY et al., 2006), muitas vezes contraditórios? Ou seria melhor pensar que desvelar suas práticas, escancarando as portas de sua sala de aula, seja a melhor forma de contá-la? Banaliza-se (NACARATO et al., 2015) ou, pelo contrário, torna-se autêntica ao ousar aprender outros olhares sobre si? Uma coisa é certa, durante a contagem, inaugura-se uma professora reinventada em suas subjetividades. Este é um processo autopoiético (PASSEGGI, 2010).

Como professora, ao fechar a porta de minha sala de aula, sinto um enorme sentimento de solidão. Sim, estou acompanhada de meus adoráveis alunos. Sim, tenho colegas que também se interessam muito pela educação matemática destas crianças. No entanto, sinto que luto com algo que é maior do que eu. Luto contra o senso instituído de que a matemática deva ser ensinada de uma única forma, sem observar o aprendiz. (BRIÃO, 2015, p. 243, tradução minha).

Escritas de si, que nada mais são que a escritura de uma autobiografia ou de uma narrativa de vida, podem ser bastante desafiadoras para um professor de matemática. Pelo menos o foram para mim. Catapultada de zonas de conforto à momentos de tensão em minhas ações docentes, me aventurei a contar-me tanto no sentido de enumerar-me quanto no sentido de desvelar-me. Junto às narrativas encontrei uma forma de refletir profundamente sobre as minhas práticas, trazendo à tona as memórias que me constituem como me tornei, nas decisões tomadas na complexidade de uma sala de aula.

Quando resolvi realizar uma pesquisa narrativa, com certeza já estava no meio de toda uma situação emblemática: estava escrevendo uma tese de doutorado em formação de professores. Mas o que esta "experiência em formação" (PASSEGGI, 2011) de pesquisar sobre experiências poderia me trazer? O que eu inaugurei nas percepções sobre as minhas práticas docentes? "Na narrativa, o autor traz os significados que atribui ao mundo vivido e à relação entre esse mundo e a interpretação que faz dele; entre a experiência humana e 0 ato de narrar; entre a história individual e a história coletiva" (NACARATO; PASSEGGI, 2013, p. 290). Inaugurei práticas significativas. Inaugurei um novo olhar sobre a minha formação docente, esta que é similar a tantos professores de matemática.

Após alguns problemas com o meu projeto de pesquisa original, que se tratava de investigar que papel a minha prática como formadora assumia no repensar de práticas de outros professores, mudei de rumo. Resolvi que antes de pesquisar práticas junto a outros docentes, eu deveria pesquisar as minhas próprias ações quando professora de matemática da educação básica e formadora (CLANDININ, 2013), em um estudo de si. Uma manobra insubordinada criativa em pesquisa (D'AMBROSIO; LOPES, 2015), que se mostrou o caminho viável para que minha identidade docente fosse preservada, ao mesmo tempo que repensada, reconstruída, implodida de dentro.

Eu ainda não estava preparada para pesquisar os professores de forma que a minha pesquisa ressoasse em nossas práticas. De forma que minhas investigações e conclusões fossem experienciais, falando diretamente com eles, e comigo. Gostaria de fazer pesquisas que fossem relevantes para a nossa profissão. Com isto, não quero dizer 
que minhas histórias e pesquisas sejam heroicas e salvadoras, só quero me sentir contribuindo para fazer parte de algo transformador. Percebi em meu contar-me, que este tipo de investigação contribui para a ressignificação da docência do leitor, quando a narrativa de vida ressoa em sua própria vida de professor. Neste espaço-tempo, existe o transporte deste leitor ativo a um lugar de reflexão no resgatar das suas próprias memórias significativas.

A experiência, segundo Larrosa (2004, p. 163) é "aquilo que nos passa, ou nos toca, ou nos acontece e, ao nos passar nos forma e nos transforma". O cuidado com o texto para que, além de uma narrativa de vida de uma professora, este pudesse ser experiencial para quem lê, assim como para quem escreve, foi um dos meus guias na construção do trabalho autobiográfico.

Essa perspectiva autobiográfica em um pesquisador narrativo é de fundamental importância. Como se trata de uma investigação que busca compreender subjetividades, esta se torna impregnada de quem a escreve: é relacional, é visceral, é inaugural. $\mathrm{O}$ pesquisador precisa se conhecer durante o processo, pois esta agora será a sua história de como lidou com a história do outro.

E por que não considerarmos uma pesquisa narrativa autobiográfica? Esta na qual o próprio pesquisador se transporta para o lugar de pesquisado. Desta forma, obtendo uma história de como lidou com sua própria história e com as intervenções de seus companheiros de jornada, que darão o tom autoformativo da pesquisa. Este foi o meu percurso metodológico.

Perguntas importantes então se fazem nesse contexto: quem é o pesquisador nessa história? O quanto dele se faz presente? (CLANDININ, 2013). A pesquisa narrativa se realiza no encontro entre pesquisado e pesquisador, o primeiro não mais como um objeto de pesquisa, mas como um sujeito. $E$, sendo assim, suas visões de mundo e como se relaciona com a sua docência se tornam muito importantes para a pesquisa e, consequentemente para o pesquisador que começa todo um processo de empatia e/ou de apatia ao que é contado. Podemos descrever esse processo como relacional.

Para alguns pesquisadores, não bastam somente histórias pontuais para começar uma investigação narrativa, estas devem ter um fundo transformador, visceral. Assim, transcendendo o sujeito que as conta, a ponto de colocar as suas decisões em um contexto social mais amplo, podemos ultrapassar narrativas de ação para genealogias de contexto (GOODSON, 1996; BOLÍVAR, 2014). Para estes autores, devemos passar de relatos de vida para histórias de vida, o que quer dizer que a narrativa deve ser enriquecida com contextos mais amplos que não se atentem somente ao protagonista. Muito da pesquisa em histórias de vida se coloca nesses termos de superação do indivíduo a um sujeito consciente de sua historicidade. Afinal, esperamos "Relatos autobiográficos sim, mas reelaboração biográfica também" (BOLíVAR, 2014, p. 119). Para Passeggi (2010), "narrar é humano e (auto)biografar um processo civilizatório".

Se somos filhos de nosso tempo, mais do que filhos de nossos pais, a ressignificação da experiência vivida, durante a formação, implicaria encontrar na reflexão biográfica marcas da historicidade do eu para ir além da imediatez do nosso tempo e compreender o mundo, ao nos 
compreender: Por que penso desse modo sobre mim mesmo e sobre a vida? (PASSEGGI, 2011, p. 149, grifos da autora).

Este sujeito antes crente ser senhor de suas ações, percebe-se um sujeito histórico que faz parte de um organismo maior, do qual é um potencial transformador, situado em seu tempo, espaço e comunidade. Há um alargamento de consciência, onde o sujeito consegue se colocar no mundo de forma coletiva. Este sujeito da experiência (LARROSA, 2004) inaugura a sua presença no mundo cotidianamente (FREIRE, 1996), assim como novas possibilidades de ação consciente diante do contexto encontrado. Vale dizer que esta inauguração não ocorre sem tormentos ou dúvidas.

$\mathrm{Na}$ tentativa de uma representação com a qual outros professores pudessem se identificar, o processo de lapidar parágrafos, acolhendo palavras significativas para mim, me trouxe momentos contínuos de dúvida sobre a quantidade de dimensões que caberiam em uma simples folha de papel. Via saltar das frases, cheiros, cores, sabores e lembranças em um processo caótico de escolhas. Experiências foram convertidas em abundância de energia criativa.

Clandinin (2013) cita um espaço tridimensional para a pesquisa narrativa, pautado em temporalidade, lugar e relações sociais. As dimensões desse espaço podem ser explicadas por Gonçalves e Nardi (2016) como: a dimensão temporal, que é relativa ao presente, passado e futuro; há também uma dimensão relacional, que é pessoal e social; e finalmente ainda há uma terceira dimensão que é a situacional, que lida com lugares ou sequência de lugares nos quais a experiência se passou. Me parece que três dimensões é pouco para a imaginação de uma contadora de histórias.

Como a minha pesquisa narrativa é autobiográfica, pesquisado e pesquisador se fundem em mim. Para me ver do avesso, em uma tentativa de transcender um relacionamento simbiótico, porém de colaboração mútua entre pesquisador-pesquisado, convidei além do leitor idealizado, alguns companheiros de jornada para se debruçarem sobre $o$ texto-roteiro e interagirem com o que nele estava escrito. Aos poucos 0 cenário experiencial foi se formando.

As vozes de meus companheiros de jornada, transbordavam do texto, "ventriloquadas" por mim. Naquele momento essas vozes eram minhas também! E ao tomar posse dessas interações me empodeirava em minha jornada de professora. Em um processo intenso de escolhas em um pensar narrado, lancei mão também de diversos artefatos para a investigação, fossem estes fotos, contos, filmes, livros, conversas, gravações de áudio. Outras vezes, para extrapolar o papel limitante de dimensões, rompendo barreiras, tive que colorir, sussurrar, escrever cartas ao leitor, dicionário e até uma tentativa de conto literário. Também silenciei infinitos particulares (MONTE, 2006) ao mesmo tempo que ousei abrir as portas de minha sala de aula.

Ao vislumbrar me tornar uma pesquisadora narrativa, aprendi a pensar com histórias, e não sobre histórias (CLANDININ, 2013). Desta forma, chegamos como pesquisadores no meio das experiências e quando colocamos um ponto final na escritura do trabalho, este é simbólico, pois também será no meio de uma história que ainda tem desdobramentos. Nessa formação como pesquisadora, também me encontro mais uma vez professora e formadora, reafirmando minhas escolhas e reconhecendo identidades. 
Uma teoria educacional viva (WHITEHEAD, 1989) foi emergindo conforme o que eu ia escrevendo no papel ia ganhando forma como um pensar narrado.

Para Whitehead (1989), essa teoria educacional ganha vida durante um processo cíclico que sempre começa com a pergunta "como melhorar a minha prática?", ou seja, com uma vontade de reflexão. Ainda conforme o autor, podemos descrever o ciclo deste movimento vital, que vai ganhando corpo primeiramente conforme observamos contradições ao experienciarmos problemas quando nossos valores são negados em nossas práticas; o processo continua com a ação de imaginar formas de superar os problemas encontrados; logo após vem o ato de escolher uma solução para esses problemas; em seguida a avaliação dos resultados dessas ações escolhidas; até que finalmente, modificam-se os problemas, ideias e ações a partir das avaliações feitas, fechando um ciclo e recomeçando um outro.

Para mim, este é um processo para compreender as minhas práticas, muito mais do que melhorá-las. Não vejo o trabalho do professor como algo evolucionista, pois "o magistério é uma atividade não-rotineira, conduzida de forma colaborativa" (POLETTINI, 1999 , p. 248) e inaugurado a cada dia, a cada turma, a cada contexto escolar. Durante a pesquisa, queria estruturar a minha prática como professora e formadora de maneira a compreender minhas escolhas, em geral fundamentadas em lembranças de outros tempos. Vale dizer que essas lembranças são muito mais reais quando observadas da forma criativa como me utilizo delas em minhas práticas hoje. Importa menos se são verdadeiras e mais o quanto estas estão presentes em meu dia a dia, da forma como as imagino. Pois, como William Thomas sugere, "se os homens definem [narram] uma situação como real, ela é real em suas consequências" (PASSEGGI, 2010, p. 112). Pensar narrativamente, neste contexto educativo:

É buscar, no passado revivido e narrado, saberes que foram apropriados e podem ser valorizados para a constituição de uma prática futura ou saberes que precisam ser desconstruídos e ressignificados por trazerem elementos que continuarão a perpetuar uma matemática escolar desprovida de significados para novas gerações de estudantes. A narrativa possibilita que se conheça o ideário pedagógico dos professores e quais contextos vividos e experienciados contribuíram para a constituição desse ideário. (NACARATO; PASSEGGI, 2013, p. 291).

Mais adiante, trarei algumas reflexões que foram possíveis graças a jornada empreendida. Porém antes, gostaria de fazer algumas considerações sobre os caminhos escolhidos durante a confecção deste trabalho e sobre a pesquisa narrativa autobiográfica em si. Fecho esta seção, com um fragmento de um conto de Borges (2000), "- O segredo, ademais, não vale o que valem os caminhos que a ele me conduziram. Esses caminhos devem ser trilhados".

\section{Alternativas de Formação nas Escritas de Si}

Para a tese, eu queria escrever um texto que se assemelhasse ao jeito descontraído com o qual encaro o meu trabalho. Nada de relatórios com linguagem difícil e recheado de distanciamentos. Com título "Eu, uma professora de matemática em jornada narrativa em busca de meus eus-professores em autoformação", optei por 
escrever um livro para os professores em geral, especialmente os de matemática, me incluindo na lista. De forma leve, vou repassando momentos importantes em minha vida e que acredito que contribuem para a minha busca por compreender minhas práticas, que quando narradas se tornam experiências de formação. No texto principal, não há referências nas poucas citações que utilizo de outros, pois as trato como parte de quem sou.

Paralelamente, em inúmeras notas de rodapé, conto uma outra história, esta em um formato mais acadêmico. Por lá dou os créditos às referências citadas, assim como analiso passagens que me remetem a outras possibilidades de observar o que foi dito, rememoriado, trazido à tona. Conforme o pesquisador vai pensando com as histórias reconstruídas: possibilidades de formação se produzem em uma aprendizagem biográfica. Procurei escrever um trabalho relacional com um processo dialético entre 0 texto base e as notas de rodapé.

A preocupação primordial é que elas [as narrativas autobiográficas] sirvam, essencialmente, a quem escreve. Admite-se, como princípio, que as escritas de si, longe de comunicar o que já se sabe, constituem-se verdadeiros processos de descoberta. Essa dimensão heurística permite a quem escreve explicitar as experiências e transformar saberes implícitos em conhecimento (pesquisa). O narrador, ao redescobrir-se como ser aprendente, reinventa-se (formação). Nesse processo hermenêutico permanente de interpretação e reinterpretação dos fatos, o adulto reelabora o processo histórico de suas aprendizagens (ação). É nesse sentido que se pode falar de aprendizagem biográfica. (PASSEGGI, 2010, p. 115).

Para o livro, faço diversos recortes na narrativa. Durante os percursos que narro, cinco no total, sinto a necessidade de ganhar fôlego em diversos momentos, e para tanto, trago três narrativas base que vou costurando na escrita: os relatos de vida; a narrativa de minhas práticas no curso de extensão intitulado "Diálogos possíveis com professores de matemática em início de carreira com uma formação reflexiva" ministrado em minha universidade; os meus espantos diante do que está sendo construído, que pode ser entendido como a minha análise do texto na posição de professora, como também formadora, para logo vê-lo como pesquisadora. Tudo isto é temperado com as observações imprescindíveis de meus companheiros de jornada. Essas pessoas, heroicas para mim, leram versões do livro-tese, experienciando-o com uma única recomendação: façam os comentários que acharem necessários, mas que por favor, observem se o professor está sendo tratado com todo o cuidado que merece (acolhimento).

O curso de extensão fez parte de minha produção de dados para o projeto original, do qual não darei mais detalhes aqui. Com carga horária total de 30 horas, o curso contou com cerca de vinte participantes entre professores em formação inicial e já em exercício. Durante os encontros, discutimos diversas tendências em Educação Matemática, assim como contos literários e documentários que disponibilizei para todos. Junto àqueles professores, e ouvindo depois as gravações, comecei a perceber um enorme interesse em minhas escolhas como docente. Que práticas eram aquelas?

Justifico minhas escolhas, tal e qual Clandinin (2013) exige quando nos engajamos nas pesquisas narrativas: de forma pessoal, prática e social. Pessoalmente, a pesquisa 
narrativa autobiográfica que descrevo, me forma, me informa e me transforma. Na prática, essa formação faz com que o meu olhar sobre a docência se torne mais autêntico e consciente, representado em um esforço ainda maior em minimizar contradições entre crenças e práticas. E, finalmente, do ponto de vista social, creio que um trabalho assim impulsiona outros professores a fazerem o mesmo, retirando-os de uma posição de invisibilidade profissional. O convite ao professor está feito, pois queremos conhecer as práticas docentes de dentro da sala de aula com o professor se produzindo, o que pode ser feito em colaboração com outros pesquisadores ou em uma jornada narrativa como a que escolhi fazer.

Para fechar estas justificativas para a minha pesquisa doutoral, transcrevo e grifo parte de uma carta ética, cujos quatro princípios-chave descritos pela Associação Internacional das histórias de vida em formação (ASIVHIF) são:

- A metodologia biográfica pode ser proposta, mas nunca imposta. Ela deve repousar sobre um contrato;

- $\quad$ O acompanhador (pesquisador ou profissional) já fez ele mesmo sua história de vida, no todo ou em parte;

- $\quad$ O produto pertence primeiramente ao autor-produtor, com utilização possível negociada;

- $\quad$ Enfim, a interpretação deve ser prospectiva, instauradora de sentido e de projeto, mais do que retrospectiva e redutora de forma causal. (PINEAU, 2012, p. 141, grifo meu).

Voltando a falar da arquitetura da narrativa, o quebra-cabeças da pesquisa é formado por cinco longos percursos cronológicos intitulados: "Pirulito multicolorido" - lida com a infância; "Peça esquisita do quebra-cabeças" - traz a adolescência; "Uma astronave rumo a castelos inimagináveis" - a formação na graduação na Universidade do Estado do Rio de Janeiro (UERJ) e no mestrado em Matemática Pura no IMPA; "Trato meio desajeitado" - o início como professora e formadora; "Espetáculo pirotécnico" descobertas como professora-formadora-pesquisadora. Para escrevê-los, observei intuitivamente certas etapas durante o processo inventivo de escritas de si, as quais descreverei a seguir.

Segundo Pineau (2012), a tríplice mimese de Paul Ricouer, que problematiza a construção histórica do sujeito, "ajuda a situar, poderosamente, o lugar da narrativa de si na formação humana: prefiguração da narrativa numa experiência temporal vivida; configuração narrativa que ela provoca; e enfim a refiguração da vida que ela acarreta" ( $p$. 142). Para Passeggi (2011), as etapas da prefiguração, configuração e refiguração podem ser compreendidas no processo de observar experiências em formação, respectivamente, segundo as perguntas: "Que experiências marcaram a minha vida intelectual e profissional?"; "O que essas experiências fizeram comigo?"; "E agora, o que faremos com o que isso fez de nós?". Assim, podemos pensar que "as experiências evocadas de forma aleatória na primeira unidade articulam-se no enredo da história, na segunda, e são reinterpretadas na terceira, graças ao distanciamento permitido pelo texto e pelo mundo humano construído no texto." (PASSEGGI, 2011, p. 152).

Enquanto isso, Clandinin (2013) expressa as fases da constituição do texto da pesquisa narrativa como um processo que evolui dos textos de campo, que logo se 
estruturam em textos provisórios de pesquisa, para chegar finalmente a textos de pesquisa. É importante observar que esse é um movimento de certa forma artístico, o que guarda muitas semelhanças com a profissão do professor, porém que enseja uma certa intencionalidade do pesquisador.

O primeiro momento da escrita do texto foi de muita confusão. Muitas ideias se embaralhavam no papel. O que escrever? Por onde começar? Fiz uma linha da vida, onde coloquei momentos nodais que acreditava essenciais para o trabalho. $E$ assim estruturei o roteiro do que gostaria de escrever. Esse foi o momento de pré-figuração, ou de escritas de textos de campo e retomadas de diários e artefatos mais antigos. Sentia vergonha dos áudios do curso de extensão e recusava ouvi-los, queria fechar as portas da minha sala de aula.

O momento da configuração ou, simplesmente, figuração, foi o momento da montagem do cenário, construindo textos provisórios da pesquisa. Nesta etapa da pesquisa e da escrita do texto, foi necessário que meus companheiros de jornada fizessem a leitura e discussão das versões do texto que eu já tinha prontas para que novos olhares se configurassem e para estimular minhas produções de si. Comecei a sentir mais interesse nos áudios que tinha do curso, que evidenciavam aspectos de minha prática como formadora, me produzindo também.

$\mathrm{Na}$ refiguração, pude analisar diversas passagens do texto. Nessa etapa, decidi voltar a ouvir os áudios, desta vez gostando e respeitando o que ouvia. Algo havia mudado, eu estava constituindo o meu texto de pesquisa. Pude, a partir daí, perceber teorias educacionais vivas, que se movimentavam junto comigo e das quais logo falarei, quando discutir alguns "resultados" dessa aventura autobiográfica, que podem ser expressos em teorias educacionais vivas.

Apesar de ser uma professora já com alguma experiência, já são mais de dez anos de sala de aula, com alegria constatei que ainda permaneço vulnerável a novas experiências no ambiente de aprendizagem que é a escola. A experiência da aprendizagem permeia todo o texto da pesquisa, posso dizer que é onde localizo o tema do trabalho, seu fio condutor. Mesmo na infância pré-escolar discuto questões que são caras à escola: os momentos de aprendizagem. Há a constatação de que muitas de minhas ações são movidas pela arte de aprender experienciando com o mundo e a partir dele.

Considero então, a pesquisa narrativa um solo fértil para a compreensão do professor de matemática e da arte de suas aprendizagens, e a sala de aula se apresenta assim como um ambiente criativo, vivo e encantador.

Não há realidades objetivas passíveis de serem conhecidas; as realidades criam-se e constroem-se no intercâmbio psicossocial da sala de aula. As percepções, apreciações, juízos e credos do professor são um fator decisivo na orientação desse processo de produção de significados, que constituem o fator mais importante do processo de construção da realidade educativa. (GÓMEZ, 1995, p.110).

Neste contexto, pelo fato das pesquisas narrativas se tratarem de um híbrido entre arte e pesquisa (KIM, 2016), uma nova perspectiva é somada às pesquisas que temos 
sobre o professor. Uma perspectiva de dentro. Esta não é objetiva como muitos clamam quanto à neutralidade de suas pesquisas, como também não é totalmente arte. É um híbrido que se "metamorfosea" entre esses dois mundos. Me pareceu uma escolha perfeita de pesquisa pois é "guiada pelo desejo de considerar o que a pessoa [professor] pensa sobre ela e sobre o mundo, como ela dá sentido às suas ações e toma consciência de sua historicidade" (PASSEGGI, 2010, p. 113).

A partir dos anos 2000, o movimento biográfico brasileiro na Educação tomou uma forma ainda mais expressiva. Pesquisas (auto)biográficas se estabelecem como método de investigação qualitativa, no meu caso de minhas práticas docentes, como também um dispositivo de formação. O narrar vidas de professores traz então outras nuances sobre esses sujeitos e suas experiências.

Pesquisa narrativa como pesquisa baseada em arte produz um modo de conhecimento uma vez que transmite verdades (múltiplas, verdades parciais) ao leitor por meio de uma experiência artística. Esse tipo de conhecimento deve ser distinguido da tradicional, pesquisa positiva que foca em reforçar certezas com o objetivo de produzir verdades absolutas. (KIM, 2008, p. 259, tradução minha).

A pesquisa narrativa é, para Passeggi (2010), antes de tudo uma "posição epistemopolítica" que busca saber mais sobre o indivíduo em suas subjetividades, superando uma concepção fragmentada do mesmo. Importante observar, que esse posicionamento não pretende ir de encontro as outras formas de conceber 0 conhecimento científico, o enriquece.

O processo de escritas de si requer muitas renúncias ao solo seguro do paradigma hegemônico das pesquisas científicas. Lugar este, onde se clama que a eliminação da subjetividade do pesquisador torna em ciência verdadeira o que este investiga. É um mito pensar que o pesquisador possa ser objetivo em seu trabalho, sem influências de suas crenças, atitudes e valores, que certamente interferem diretamente em suas escolhas a cada passo da investigação (BRIÃO, 2016, p. 1).

Portanto, a pesquisa narrativa autobiográfica, enquanto pesquisa realizada sobre si pelo próprio pesquisador, pode ser considerada insubordinada criativa. Esta forma de pesquisar traz elementos novos à nossa forma de conhecer o professor, suas diversas formações e suas práticas, ainda que muitas vezes contraditórias. $O$ foco de pesquisas assim é o olhar o professor como este se vê e compreender junto com ele (o próprio pesquisador), como se tornou o docente que é.

\section{Por uma Urgente Pedagogia da Identidade Docente}

Como trabalho em um Instituto de Aplicação, tenho a oportunidade de rever práticas, estar junto a professores em formação, formar e ser formada, discutir educação. Nesse instituto, trabalho tanto com Educação Básica quanto Superior, na formação de professores.

O modelo de formação de professores na UERJ, é singular. O licenciando mantém contato com pelo menos quatro institutos enquanto estudante da universidade: o Instituto de Matemática e Estatística (base), o Instituto de Física, o Instituto de Educação e o 
Instituto de Aplicação. Cada instituto está encarregado de uma parte da formação desse futuro professor, com disciplinas específicas. Onde trabalho, temos a responsabilidade de lidar com disciplinas de práticas pedagógicas na Educação Básica e estágios. E, como o instituto abriga um colégio de aplicação, nele os licenciandos em Matemática realizam três dos seus estágios. Nem sempre foi assim, como quando fui aluna da UERJ na época que o instituto ainda era tão somente um colégio de aplicação.

Quando comecei a trabalhar no instituto na formação matemática e pedagógica de futuros professores, rapidamente percebi que o que faço tem muito a ver com uma desconstrução, autoritária, vale dizer, de equívocos de compreensão que estes carregavam desde a escola. Ao trazer outros olhares sobre assuntos fundamentais da matemática escolar, penso que tentava trazer também a forma "natural" como a matemática ia sendo construída por mim quando criança. Para ilustrar, trarei alguns fragmentos de minha narrativa.

- Agora sinto vontade de falar das férias na casa de meus avós, pois quando estava na casa deles, meu avô às vezes fazia contas escondido comigo. Esse era nosso segredo. Eu não devia ter nem cinco anos de idade, quando ele fazia contas na parede com um "cotoquinho" de lápis, que cuidadosamente apagávamos depois. Não queríamos ser pegos. Naquela época, começo dos anos oitenta, lápis na casa simples de meus avós era um objeto de luxo e deveria durar até seu último suspiro, se é que se pode falar assim de um lápis. E na parede que não via tinta havia anos, eu via diversas cores, mas principalmente um verde-rosa desbotado, que se misturava com as continhas de mais e de menos de meu vô. Não lembro de como ele fazia as contas, ou porque ele fazia contas... o dinheiro de seu ofício de padeiro era tão curto... divagando um pouco, talvez fosse um vislumbre do futuro de sua neta: ela seria uma professora de Matemática. - Podemos pensar que essa foi a minha formação inicial na profissão? (BRIÃO, 2017, p. 48).

Fosse nas continhas do meu avô, um padeiro com pouco contato com a escola, mas que sim, como toda e qualquer pessoa, com sua visão matemática de mundo; fosse na contagem de lagartixas empreendida por minha mãe em sua infância, as brincadeiras infantis na rua, os jogos de tabuleiro muito presentes em casa, o fato é que eu aspirava a forma matemática de estar no mundo das pessoas ao meu redor. Esta "matemática de outros" se apresentava a mim de forma singela, divertida e autêntica. Cada um lidava com suas construções de compreensão da forma que podiam.

Aos poucos já na idade escolar, isso foi adormecido. E foi colocado algo no lugar, uma matemática instrumental, fora de contexto, apostilada, dura, "neutra", de pouca compreensão, distante das pessoas comuns, de quem era essa matemática? Em meados da década de oitenta entrei na escola, pois já estava com a idade obrigatória na época (art. 20, Lei oㅜ 5.692/1971): sete anos. Para a minha criativa e geógrafa mãe, que me alfabetizou e me mostrou um mundo incrível que se descortinava para mim e para o meu pai, enxadrista e bancário, homem inteligente e dos números, lugar de criança é com a família, brincando! E foi brincando que o mundo se apresentava para mim de uma forma diferente, muito diferente do que me contavam na escola.

A adolescência foi um período difícil, falando especificamente da escola, esta ficou cada vez pior e incompreensível. Mas ainda tirava as melhores notas da turma. Tudo era 
muito fácil, ainda que sem sentido. Era só decorar... e com o tempo isso foi perdendo a graça.

O ensino tradicional era a regra. - Ensino tradicional? - Sim, é um tipo de ensino que privilegia $o$ conhecimento pronto e não o produzido socialmente. Esse tipo de ensino parece não ter muito a ver com a aprendizagem. Na minha forma de ver, seu objetivo maior é impor uma forma de conhecer em detrimento de toda a riqueza de ideias que há em um conjunto de pessoas dispostas a aprender algo. Mas, você não sabia? (BRIÃO, 2017, p. 84).

Quando chego na faculdade, novamente encontro pouca explicação sobre o que está por trás das coisas. Só uma matemática ainda mais abstrata, com professores ainda mais distantes. O curso carecia de identidade docente. Era dado por professores de um Instituto de Matemática, onde pouco se discutia sobre o que era lecionar na Educação Básica. Algo tão fundamental era tratado como menos importante, e era deixado para os últimos períodos.

Ironicamente, durante a minha formação inicial como professora, fui preparada para ser matemática. Essa foi a identidade que consegui no curso, e assim fui fazer o mestrado em matemática ainda cursando a graduação. Digo isto porque nos primeiros dois anos de curso, vi somente matemática, sem nenhuma relação com a escola. Eram cursos comuns que misturavam bacharelandos e licenciandos em uma "formação Frankenstein". Achei que ser matemática seria a única saída para tais desabrigos.

Fui formada para me transformar em alguma outra coisa, sem nenhuma valorização da matemática que eu construíra durante meus anos escolares ou em minha infância. Sem nenhuma discussão sobre os meus interesses, sobre o porque de eu ter escolhido ser professora de matemática. Sentia que queriam me moldar a alguma outra coisa. Não era mais singela aquela matemática que apresentavam forçosamente a mim. Era isso, uma formação de moldes, todos iguais - como foi em algumas escolas por onde passei. O que me movia como professora era a vontade de acolhimento, mas isso não me foi perguntado. Violências simbólicas do não ser, em relações de poder desfavoráveis ao futuro professor, com o imenso e não incomum perigo de serem reproduzidas nas escolas.

Não vejo a educação matemática no Brasil atingindo níveis de qualidade aceitáveis nos próximos anos. É uma visão pessimista, mas o que me parece é que estamos formando um professor para uma escola idealizada (muitas vezes por gente que não sabe de escola), ao invés de formá-lo para a escola real com a qual este terá de lidar em seu cotidiano. Uma escola com salas de aula abarrotadas... crianças desmotivadas... carente de recursos... esse professor tem que ser criativo, ter um bom ouvido, habilidade para lidar com realidades tão diversas das suas. Ele tem que aprender a policiar seus preconceitos, pré-julgamentos, ignorâncias, frustrações, sentir empatia. Temos de nos conhecer.

Ao ser formado em um ambiente de respeito, que valoriza as suas identidades, esse professor terá experienciado um ambiente ético de diferenças. Ao ter exposto suas opiniões e ter discutido sobre elas em um amplo espaço de debate sobre a docência, esse professor terá dado o primeiro passo para refletir sobre suas práticas em suas salas 
de aula. A docência é algo muito pessoal, por isso talvez queiram neutralizar a pessoa do professor, o transformando em alguma outra coisa, em cópias de nós formadores. Depois de todo esse caminhar narrativo, penso que desabrochamentos seriam melhores do que tais desfigurações.

Falando ainda da faculdade, como disse, senti que fazia um curso que não tinha uma identidade definida. Como eu conseguiria construir a minha identidade docente ali? Onde estavam as discussões sobre docência, sobre escola, sobre o nosso papel como educadores matemáticos?

Tente imaginar a cena comigo. Uma professora cheia de si, com fome de futuro, em início de carreira, idealizando que dar aula seria moleza. Afinal, era só saber o conteúdo e ela estava bem segura de que o dominava. Tudo bem, saímos da universidade muitas vezes com essa ilusão: é só saber o conteúdo! Foi quando o meu mundo de cristal quebrou ao me deparar com crianças em pé (não, elas não estavam ansiosas em me ver), brincando (não, elas não queriam ter aula de matemática), conversando com o colega de trás (não, a visão de sala de aula delas era outra, eu era a intrusa ali). Uma turma enorme... tal e qual quando eu ainda era criança e chegava de volta ao Rio de Janeiro no início da década de 90: minha turminha iria conter muita gente. Depois te conto. Mas, enfim, era o caos! Senti que iria chorar. Ainda me lembro desse dia... quando voltava para casa com a cabeça baixa e todas as minhas esperanças esfarrapadas bem no fundo de meus bolsos. No que é que eu tinha me metido afinal? (BRIÃO, 2017, p. 36).

Essa formação refratária me impediu por muito tempo de enxergar as contradições que essa mesma formação apresentava com a minha forma de ver o mundo. Eu não queria um mundo repleto de hierarquias, que retira o sujeito da equação, silenciando identidades. As histórias de vida de professores tentam trazer o professor novamente para o palco (GOODSON, 1996), como um protagonista de suas ações e de suas aprendizagens e coparticipante das relações que media junto aos alunos.

Pedagogicamente, como formadora, eu tentava trazer um pouco dessa espontaneidade com que todos nós construímos matemáticas em nosso dia a dia. Me tornei uma professora construtivista (D'AMBROSIO; STEFFE, 2014) na educação básica, que construindo modelos da matemática viável de meus estudantes, os pesquisava, dialogando com as suas visões de mundo.

[...] Me parece que a maior regra é não seguir regra alguma. Tudo bem, já vejo a contradição aí, mas o que quero dizer é que a autenticidade em minha prática é o mais importante para mim. E esta prática está sempre sendo construída na relação com o educando, pautada no respeito pela criança e por suas trajetórias. A exposição de minha arte de ensinar matemática é o que me torna autêntica. Nas salas de aula por onde atuo, me vejo como uma coprodutora de práticas de ensino junto aos meus estudantes. Procuro ser uma pesquisadora atenta da matemática de meu aluno. (BRIÃO, 2017, p. 22).

Ideias construtivistas que já permeavam a minha prática docente na Educação Básica não viam eco na formação de professores. Uma contradição viva (WHITEHEAD, 1989), uma vez que eu queria trazer um pouco de minha prática docente para os licenciandos, mas não o fazia de forma construtivista! D’Ambrosio e Kastberg (2012) já 
afirmavam que para tal empreitada, se faz necessário construir modelos dos eusprofessores desses estudantes. Um formador construtivista legitima e se sente curioso quanto aos processos identitários dos futuros professores.

Constatei que não estava valorizando o professor, fosse na formação ou nas pesquisas. Eu precisava parar de olhá-lo com desconfiança, de um posicionamento de dúvida, pensando que ele iria fazer do mesmo jeito que fizeram comigo... E aí surge uma das contradições mais importantes de meu trabalho, esta já observada no trabalho de D'Ambrosio e Kastberg (2012), acreditar no ensino construtivista e trabalhar assim com as crianças, mas não ser construtivista na formação de professores, apesar de exigir deles uma identificação com essa prática.

Trazendo um panorama geral como formadora, eu era autoritária, inquisidora e diminuía a autoestima dos futuros professores sempre os avaliando por baixo, focando no que não sabiam (tal e qual experienciei em minhas muitas "formações"). Tentava os despir do que eram para colocar algo, em meu ponto de vista, melhor no lugar: a professora que eu era com as crianças (afinal acreditava que precisava defender os estudantes desses "professores cruéis", que minariam potencialidades). De certa forma eu participava de algo maior do que eu sem perceber: eu silenciava identidades. (BRIÃO, 2017, p. 22).

Surpreendentemente, me descobri várias professoras. Essa multiplicidade de eusprofessores que emergem na relação com os alunos seria um ponto de início para uma pedagogia da identidade (JENLINK, 2014). Esta trataria com a maior importância as memórias, crenças, motivações e ideias matemáticas do professor. Respeitaria seus tempos, discutiria assuntos nodais em suas narrativas de ações (GOODSON, 1996), privilegiando construções identitárias possíveis de eus-professores ainda em formação. Um formador que se utiliza de uma pedagogia da identidade, pode ser visto como um formador construtivista.

Formadores que compreendem que a formação das identidades dos estudantes são individuais também compreendem a formação de suas próprias identidades. Neste sentido, formadores de professores devem praticar uma pedagogia da identidade que criticamente examina as consequências que discursos e práticas dominantes tem tido na criação de suas próprias vidas e nas vidas de seus estudantes. (JENLINK, 2014, p. 257, tradução nossa).

Dessa forma, podemos chegar à constatação simples de que para se tornar um formador construtivista, este deve primeiramente buscar compreender seus próprios eusprofessores. A investigação narrativa autobiográfica foi o método que encontrei para a minha pesquisa.

Se desejamos provocar o futuro professor de matemática para que este construa ideias matemáticas inovadoras em sua sala de aula em coautoria com os alunos, deve haver uma formação de acolhimento que valorize a voz interna desse licenciando, que alie a voz da disciplina com as vozes das crianças (D'AMBROSIO, 2004). Em um processo hermenêutico de escuta, suspendendo a dúvida e desempacotando a matemática formal para compreender melhor a matemática das crianças, o professor 
pode ousar em provocar aprendizagens. Um formador construtivista deve ouvir essas vozes.

Nesse sentido, a observância de que a prática do professor é "uma atividade reflexiva e artística, na qual cabem algumas aplicações concretas de caráter técnico" (GÓMEZ, 1995, p. 100), vai de encontro com jeitos frios e distantes de lecionar encontrados na universidade, que alimentam o ciclo de professores ditos "neutros" e que massacram as crianças nas escolas. De forma biográfica, portanto reflexiva e artística, podemos elaborar contra-memórias (BUENO et al., 1993), que desconstroem ideologias para a profissão. Estas memórias alternativas valorizam o professor e sua construção de identidades e biografias, demolindo concepções de outrem que não se encaixem em suas visões de mundo e de educação, problematizando-as. Isto tem a ver com uma pedagogia da identidade.

Em um processo de formação acolhedor que observei ao escrever a minha história de vida, percebi a minha autenticidade como professora e formadora. Tive a oportunidade de analisar os ruídos que não permitiam que eu tivesse uma composição coerente com as minhas crenças em uma educação pública, de qualidade, que respeite o aluno e que potencialize a sua humanidade e capacidade de ler e escrever 0 mundo matematicamente.

Ao lançar um olhar mais detido e mais arguto sobre o seu passado, os professores tem a oportunidade de refazer seus próprios percursos, e a análise dos mesmos tem uma série de desdobramentos que se revelam férteis a instauração de práticas de formação. Tal exercício, ao mesmo tempo que os leva a desenvolver um trabalho de desconstrução das imagens que a memória oficial guardou de sua profissão, possibilita que reconstruam um modo próprio de se perceberem. (BUENO et al., 1993, p. 308).

Novamente, uma pedagogia da identidade deve valorizar a memória, que trazendo à tona contra-memórias desmistificam as narrativas dominantes (BUENO et al., 1993), e deixando o caminho livre para auto-insubordinações criativas. Tratarei dessa observação mais adiante.

Em 2013, quando li o artigo das professoras D’Ambrosio e Kastberg (2012), lembro do espanto causado pela constatação de algo que estava sempre presente, mas que eu não conseguia ver: o fato de grande parte dos licenciandos parecerem interessados pelas minhas ideias sobre docência mas que ao se formarem, insistirem em outras formas de ensinar, perpetuando, algumas vezes, um ensino sem significado da matemática. Como professora e formadora em um Instituto de Aplicação, eu tinha a oportunidade de ver isso acontecer todos os dias.

Segundo Nacarato e Passeggi (2013), há uma grande chance dos futuros professores continuarem reproduzindo um ciclo de práticas vivenciadas com marcas negativas com respeito a matemática, se não houver uma problematização das crenças e representações construídas durante a escolarização. Uma pedagogia da identidade se apresenta crítica a essas memórias.

$\mathrm{Na}$ próxima seção trago os desdobramentos desta trama docente na qual me vi cativa. 


\section{As Tão Fundamentais Auto-Insubordinações Criativas}

O conceito de insubordinação criativa, trazido ao Brasil por Beatriz D'Ambrosio e Celi Lopes (2015), no ambiente da Educação Matemática, trata de como um docente age de forma criativa em favor de seus alunos, para contornar uma situação criada por terceiros que em sua opinião não seja boa para a aprendizagem matemática. Podemos perceber que este conceito está no plano da ação.

A auto-insubordinação criativa foi percebida por mim durante as escritas de si. Uma teoria educacional que ganhou vida no contorno das palavras que escrevi sobre minhas práticas. Como trabalho em um instituto onde tenho muita autonomia, percebi que minha prática era muitas vezes "atrapalhada" por essa formação, já descrita, que muitas vezes não condizia com a minha maneira inicial de ver a matemática. Lutava contra algo que havia sido instituído em mim e, que eu colaborei para tanto, ressignificando o que me era imposto. É claro que estou falando de certas (de)formações, porém que fazem parte da professora que me tornei.

Muitas experiências observadas e analisadas em meu narrar se fundam na ideia de um professor "construtor de utopias" (PINHEIRO apud GONÇALVES; NARDI, 2016). Assim, a ideia de desenvolvimento profissional toma nova forma como uma produção de "transformações do status quo da formação docente" (GONÇALVES; NARDI, 2016, p. 1076). Finalmente este professor idealizado pode se tornar protagonista de sua própria maneira de lidar com a docência e suas práticas de formação.

As narrativas de vida de professores têm o potencial de redimensionar as experiências de formação. Quando focada em construção de contra-memórias, rompendo instrumentos de dominação, temos um terreno fértil para clarear compreensões sobre nossas escolhas docentes. Essa desconstrução de ideias impostas deixa o caminho livre para auto-insubordinações criativas cotidianas expressadas por meio da reflexão autobiográfica realizada sobre essas memórias alternativas. Devemos estar atentos que "a reflexão implica a imersão consciente do homem no mundo da sua experiência, um mundo carregado de conotações, valores, intercâmbios simbólicos, correspondências afetivas, interesses sociais e cenários políticos.” (GÓMEZ, 1995, p. 103). Para Passeggi (2011),

A formação, quando adota a mirada reflexiva sobre a experiência vivida, em nenhum momento, deve ser entendida como uma (trans)formação sem crises. Ela adota, ao contrário, na perspectiva dialética, uma dimensão histórica, em franca ruptura com os ideais iluministas, que estimavam um aperfeiçoamento linear, progressivo e a-histórico do desenvolvimento humano. Do ponto de vista psicológico da construção da subjetividade, as escritas autobiográficas mostram justamente à pessoa que narra essa descontinuidade, as rupturas, a imprevisibilidade, o fortuito e o papel das contingências como aspectos determinantes da experiência humana. ( $p$. 154).

Enquanto as contra-memórias te fazem lidar com resquícios de formação, ruídos e conformações sociais que produzem conflitos consigo mesmo, as auto-insubordinações criativas são ações que se realizam de forma criativa para diminuir estes conflitos visando a aprendizagem dos estudantes. A auto-insubordinação criativa atua diante da formação 
escolar que tivemos, em favor de outras possibilidades que ousem novos olhares sobre 0 educar. Há uma reinvenção de si, em constante autodesafio.

Para Knowles (1992), a biografia do professor se torna importante em um contexto de pesquisas que sugere "que não são os programas de formação de professores que estabelecem fundamentalmente a identidade do papel do professor mas, sim, experiências prévias de vida relacionadas à educação e ao ensino" (p. 147, tradução minha).

O tratar de forma reflexiva e biográfica a nossa formação, observando narrativas dominantes criticamente, desvela um novo contexto onde a auto-insubordinação criativa se faz presente. Nessa dimensão humana exposta, construímos a nossa arte de educar e temos as rédeas do nosso compromisso ético com o estudante. Fazemos o que fazemos porque acreditamos que este seja o melhor para o estudante e não porque as coisas sempre funcionaram assim.

Relato, a título de ilustração, dois momentos de conflito em minha prática docente, ambos constatados durante a minha aventura pelo bosque narrativo. Esses são exemplos de auto-insubordinações criativas. Primeiramente, me vi uma professora dividida entre práticas de enfrentamento a uma matemática neutra e sem sentido e que, ao mesmo tempo, bradava a defesa de uma matemática régia, do rigor acima de qualquer coisa. Enquanto eu buscava uma matemática menos empacotada, aquela de minha infância, construída nas discussões da sala de aula, com jogos, leituras e desafios, essa postura ia de encontro à forma como a matemática me foi apresentada na escola e na universidade: de lonjuras sem qualquer graça. Assim, me auto-desafiei a fazer do meu jeito.

Outro momento que vai na contramão de minha formação ocorre quando aprendo junto aos meus alunos. Sinto que quanto mais domino o conteúdo, não de uma forma instrumental, mas sabendo o que está por trás das coisas, mais ouso em sala de aula e mais desejo investir em minha formação humana, me preparando para aulas sempre surpreendentes. Em minha percepção, aprender com os alunos não permeava a minha formação. A auto-insubordinação criativa está nessa atuação refletida que de forma criativa vai de encontro a certas (de)formações.

A prática, como um espaço de formação refletida e consciente, abre espaço para se tornar experiência. Pois nos atravessam constituindo um processo identitário recheado de dúvidas, de desconfortos, de lugares incomuns, dos quais algumas vezes desejamos superação, em outras, que nos viram do avesso e nos faz querer explorar mais.

Valores que são negados em minhas práticas, podem ser chamados de contradições vivas. Como professora, me tornei presença em um ambiente repleto dessas contradições. Quem era eu quando professora de matemática? Quase sem perceber, fui sendo engaiolada profissionalmente. Pude observar que me auto-insubordinava criativamente para me acercar de minhas reais crenças em relação a uma matemática humanizada.

Toda a sensibilidade dessa busca por compreender práticas e formações de experiência tão contraditórias me remete ao início de minha jornada e a metáfora da árvore de Marie-Michèle. Em uma obra importantíssima publicada em 1983 junto à 
Gaston Pineau e que é considerada um dos marcos iniciais do movimento das histórias de vida em formação, Marie-Michèle constata:

Após minha narrativa de vida, tomei consciência do tutor encravado em
minha árvore. Esse tutor, eram as normas estabelecidas, as crenças, os
valores, a formação, a educação recebidas, que a escola, a igreja, a
sociedade, a família me haviam inculcado e que eu tinha contribuído a
reforçar. Esse tutor, eu o arranquei, pois ele tinha mais importância do que
a própria árvore. Eu queria encontrar minhas próprias verdades, ir à fonte...
Transplantei minha árvore numa terra mais rica onde poderia lançar raízes.
Ela precisava de água, de sol, de ar para se reerguer. Eu fui à descoberta
de seu tronco, de suas raízes, de seus ramos e de sua seiva. (PINEAU,
2012, p. 148).

O lugar fecundo para onde transferi a minha árvore para me ver livre desse tutor foi a pesquisa narrativa autobiográfica. $E$ foi graças a esse terreno fértil que contei-me como uma professora de matemática auto-insubordinada criativa. O resultado foi o desabrochar dessa árvore em uma explosão de vida que superabunda todos os dias em práticas docentes cada vez mais co-construídas junto aos meus alunos da Educação Básica, assim como do Ensino Superior.

Neste trabalho, descrevo essa teoria educacional viva que foi formada conforme me narrava. Dentro desta, está o conceito de auto-insubordinação criativa, que coloco em uma primeira aproximação, sem pretender esgotar a discussão.

\section{Referências}

BOLÍVAR, A. A expressividade epistêmico-metodológica da pesquisa (auto)biográfica. In: ABRAHÃO, M. H. M. B.; BRAGANÇA, I. F. S.; ARAÚJO, M. S. Pesquisa (auto)biográfica, fontes e questões. Curitiba, PR: CRV, 2014. p. 113-127.

BORGES, J. L. O Etnógrafo. In: BORGES, J. L. Obras completas de Jorge Luiz Borges, volume 2: O Elogio da Sombra. São Paulo: Globo, 2000. (p. 20-21).

BRASIL. Lei no 5.692, art. 20, de 11 de agosto de 1971. Fixa Diretrizes e Bases para o ensino de $1^{\circ}$ e $2^{\circ}$ graus, e dá outras providências. Disponível em: <http://www.planalto.gov.br/ccivil_03/leis/L5692.htm>. Acesso em: 08 jun. 2016.

BRIÃO, G. F. A mathematics teacher and her daily creative insubordinations. In: D'AMBROSIO, B. S.; LOPES, C. E. (Org.). Creative insubordination in brazilian mathematics education research. Raleigh: Lulu Press, 2015. p. 241-250.

BRIÃO, G F. Despertar de uma educadora matemática ao experienciar narrativamente sua história de vida. VI Congresso Vozes. Rio de Janeiro. 2016.

BRIÃO, G F. Eu, uma professora de matemática em jornada narrativa em busca de meus eus-professores eu autoformação. 2017. 321 f. Tese (Doutorado em Educação Matemática) - Instituto de Geociências e Ciências Exatas, Universidade Estadual Paulista, Rio Claro, 2017.

BUENO, B. O.; SOUSA, C. P.; CATANI, D. B.; SOUZA, M. C. C. C. Docência, memória e gênero: estudos alternativos sobre a formação de professores. Psicologia USP, São Paulo, 4 (1/2), p. 299-318, 1993. 
CLANDININ, D. J. Engaging in narrative inquiry. California: Left Coast Press, 2013.

D'AMBROSIO, B. S. Preparing teachers to teach mathematics within a constructivist framework: the importance of listening to children. In: WATANABE, T.; THOMPSON, D. R. The work of mathematics teacher educators: exchanging ideas for effective practice. San Diego, CA: Association of Mathematics Teacher Educators, 2004. p. 135-150.

D'AMBROSIO, B. S.; STEFFE, L. P. O Ensino Construtivista. Em Aberto, Brasília, ano 14, n. 62, p. 23-32, abr./jun. 1994.

D'AMBROSIO, B. S.; KASTBERG, S. Giving reason to prospective mathematics teachers. For the Learning of Mathematics, Kingston, Canadá, v. 32, n. 3, p. 22-27, nov. 2012.

D'AMBROSIO, B. S.; LOPES, C. E. Insubordinação criativa: um convite à reinvenção do educador matemático. Bolema, Rio Claro - SP, v. 29, n. 51, p. 1-17, abr. 2015.

DAY, C.; KINGTON, A.; STOBART, G.; SAMMONS, P. The personal and professional selves of teachers: stable and unstable identities. British Educational Research Journal, Wales, GB, v. 32, n. 4, p. 601-616, 2006.

FREIRE, P. Pedagogia da autonomia: saberes necessários à prática educativa. $3^{\underline{a}}$ ed. São Paulo: Paz e Terra, 1996.

GÓMEZ, A. P. O pensamento prático do professor: a formação do professor como profissional reflexivo. In: Nóvoa, A (Org.). Os professores e a sua formação. $2^{\underline{a}}$ ed. $p$. 93-114, 1995.

GONÇALVES, T. V. O.; NARDI, R. Aspectos epistemológicos da pesquisa narrativa presentes em teses e dissertações sobre formação de professores na área de educação em ciências e matemática, no período de 2000 a 2012. Atas do Congresso IberoAmericano em Investigação Qualitativa, CIAIQ, 2016.

GOODSON, I. Representing teachers: bringing teachers back in. Changing research and practice: teachers' professionalism identities and knowledge. Bristol/PA: Falmer Press, 1996. p. 211-221.

JENLINK, P. M. Teacher identity and the struggle for recognition: meeting the challenges of a diverse society. Inglaterra: Rowman \& Littlefield Education, 2014.

$\mathrm{KIM}, \mathrm{J}$. A romance with narrative inquiry: toward an act of narrative theorizing. Curriculum and Teaching Dialogue, 10 (1 e 2), 2008, p. 251-267.

KIM, J. Understanding narrative inquiry. California: SAGE, 2016.

KNOWLES, J. G. Models for understanding pre-service and beginning teachers' biographies: illustration from case studies. In: GOODSON, I. (Ed.). Studying teachers' lives. London: Routledge, 1992. p.99-152.

LARROSA, J. Linguagem e educação depois de Babel. Belo Horizonte: Autêntica, 2004.

MONTE, M. Infinito particular. Disponível em: <https://www.letras.com/marisamonte/515189/>. Acesso em: 08 jun. 2016. 
NACARATO, A.; PASSEGGI, M. C. Narrativas autobiográficas produzidas por futuras professoras: representações sobre a matemática escolar. Rev. educ. PUC-Camp., Campinas, 18(3), p. 287-299, set./dez., 2013.

NACARATO, A.; CAPORALE, S. M. M.; CUSTÓDIO, I. A. As escritas de si como prática de autoformação docente: legitimização das vozes de professores ou banalização? In: D'AMBROSIO, B. S.; LOPES, C. E. (Org.). Vertentes da subversão na produção científica em educação matemática. Campinas, SP: Mercado de Letras, 2015. p. 207234.

PASSEGGI, M. C. Narrar é humano! Autobiografar é um processo civilizatório. In: PASSEGGI, M. C.; SILVA, V. B. (Org.). Invenções de vidas, compreensão de itinerários e alternativas de formação. p. 103-130. 2010.

PASSEGGI, M. C. A experiência em formação. Educação, v. 34, n. 2, p. 147-156, maio/ago. 2011.

PINEAU, G. A tríplice aventura (auto)biográfica: a expressão, a socialização e a formação. In: ABRAHÃO, M. H. M. B.; PASSEGGI, M. C. Dimensões epistemológicas e metodológicas da pesquisa (auto)biográfica: Tomo I. Natal: EDUFRN, Porto Alegre: EDIPUCRS; Salvador: EDUNEB, p. 139-158, 2012.

POLETTINI, A. F. F. Análise das experiências vividas determinando o desenvolvimento profissional do professor de matemática. In: BICUDO, M. A. V. Pesquisa em Educação Matemática: concepções e perspectivas. São Paulo: Editora UNESP, 1999, p. 247-261.

WHITEHEAD, J. Creating a living educational theory from questions of the kind, "how do I improve my practice?". Cambridge Journal of Education, Cambridge, v. 19, n. 1, p. 4152, 1989.

Submissão: $12 / 08 / 2017$

Aceite: 07/11/2017 